\title{
Sustainability and economic security of territorial development in St. Petersburg
}

\author{
Tamara Orlovskaya ${ }^{1^{*}}$ \\ ${ }^{1}$ Saint-Petersburg state university of architecture and civil engineering, 190005, St. Petersburg, 2-ya \\ Krasnoarmeiskaya St. 4, Russia
}

\begin{abstract}
The research is devoted to improvement of the methodological tool for assessing the sustainability of the socio-economic territorial development in megalopolis based on the analysis of local budget expenditures for the development of social infrastructure and security. The purpose of the research is to determine the compliance of financial capabilities of the territory and the needs of the residents to for comfortable and safe urban environment. The paper uses methods for normalizing indicators by reducing the size scale to the dimensionless scale, comparative studies, and the results of sociological surveys. The author has calculated the coefficients of budget stability and security index for the St. Petersburg' districts, and established the nature of the relationship between the factorial indicator of tax revenues and local budget expenditures to ensure the quality of life for residents. The proposed approach allows us to assess the efficiency of budget expenditures and compare the results of statistical data and sociological surveys on the level of development of social infrastructure and security in the metropolis. The results can be used to assess the effectiveness of local budget expenditures and programs for the sustainable development of St. Petersburg.
\end{abstract}

\section{Introduction}

The development of the territories of megalopolises at the present stage is largely due to the financial capabilities of regions and cities. According to scientists, for example, N. V. Vasilyeva [1], local budgets and budgets of the subjects of the Russian Federation as sources of funding for various activities that support programs for the development of health, social services, education, and life security, are the guarantor of the independence and financial autonomy of the megalopolis.

According to [2], the main principles of efficiency of tax revenue expenditure should include: the principle of expediency (or necessity) of spending funds for a specific event or program; the principle of sufficiency of allocated funds; the principle of transparency of expenditures. Therefore, one of the most important tasks of the tax policy of the megalopolis is to ensure economic security in the form of balance between interests of society and the individual.

\footnotetext{
* Corresponding author: e-tamara@mail.ru
} 
As noted in the study [3] in relation to the state, tax security is a balance between the economic interests of the state and taxpayers. The state, as rightly noted in studies, for example [4-6], is interested in increasing tax revenues. Meanwhile, the interest of taxpayers is in the effective spending of budget funds, which is understood not only as "the greatest possible receipt of public services from the state" [3], but also as to create a safe and comfortable environment for life. So the interest of taxpayers is to ensure the standard needs of the population in housing, social infrastructure (education, health, culture and sports, social protection) and security of residence. Therefore, the effectiveness of spending tax revenues should also be considered as population assesses the effectiveness of the achieved efforts of the authorities in ensuring the quality of life of the population.

\section{Problem definition}

Tax security is one of the most promising areas of economic security in megalopolises. In fact, we are talking about assessing the effectiveness of tax policy, its impact on the formed residential environment, the ratio of the conflict potential of the territory, which, according to Pacione M. [7], each metropolis has, the impact of the created residential environment on the development of various social groups $[8,9]$.

J. Stadelbauer [10], describing the causes of conflict nodes in megalopolises, notes the importance of an adequate response of the population to the funds expenditure by the city authorities in the development of the urban environment. The study of economic security in terms of the effectiveness of tax expenditures on security, housing and communal services, education, culture, cinema, physical culture and sports, and social policy, in the context of St. Petersburg's districts, allows us to assess, first of all, the level of effective management of the territory at the local level.

The final goal of the study is to analyze the efficiency of spending budget funds to create safe and favorable living conditions for the population in various administrative regions of St. Petersburg.

\section{Data and methods}

The works of Russian and foreign scientists in the field of studying the efficiency of municipal tax policy [1-6] and conflict potential in global cities [7-10] are the science basis of the research. The author has conducted research in the context of the administrative districts of St. Petersburg and have used the database of indicators of municipalities by the Federal state statistics service, the informational and statistical database of the MIA of Russia in St. Petersburg and Leningrad Region with the study of St. Petersburg residents opinion on police activity in 2017 , materials of life security research in St. Petersburg [1112].

Following statistical indicators of the local budgets in St. Petersburg have been used to assess efficiency of budget expenditures in the districts published by Petrostat: actual revenues of local budgets and budget expenditures to ensure the life security and comfort of living, including expenditures on housing and communal services, education, culture, cinematography, physical culture and sports, and social policy. Indicators based on sociological surveys have been used to assess the conflict nodes in the districts, they are the share of residents who feel protected or rather protected from crime; the proportion of residents who feel safe or rather safe on the roads.

The level of economic security in various areas of the megalopolis has been analyzed the basis of indicators normalization by converting the size scale to the dimensionless one according to the formula [13]: 


$$
X_{i}^{\prime}=\left(X_{i}-X_{\min }\right) /\left(X_{\max }-X_{\min }\right)
$$

Where $X_{i}{ }_{i}$ - normalized value of input indicator;

$X_{i}$ - actual value of the indicator;

$X_{\min }$ - the minimum value of the indicator in the sample;

$X_{\max }-$ maximum value of the indicator in the sample.

General scientific methods of learning, methods of logical analysis and expert review, correlation analysis and comparative analysis methods, results of sociological surveys have been used in the study.

\section{Research results and discussion}

According to S. V. Yavon [14], the city is "an ideal place for conducting field research, for studying the forms and processes of urban life" [14, P. 377]. The expediency of studying the relationship between local budget expenditures and conflict zones in the megalopolis as factors for assessing the level of economic security is caused by the need to analyze the possibility of achieving strategic targets for ensuring social standards of living by financing activities aimed at the integrated and sustainable development of the territory, creating safe and favorable living conditions. A study of the consequences of the government policy of budget spending, an analysis of the public opinion about the financial efforts to develop the urban environment, allows to evaluate the effectiveness of management actions, identify budget priorities for the future.

The study of the principles of effective tax funds expenditures [2], practical activities in the field of tax policy [3-6], models of urban environment development [14-16], has confirmed the importance of improving methods for assessing the effectiveness of local budget expenditures that allow to identify the real situation and to form an adequately perceived municipal policy by the population. Methods for evaluating effectiveness, proposed by most authors [2], are based on a comparative analysis of the specific indicators of funds allocated for a specific event per person and an analysis of the level of security of minimum state standards for a group of municipalities. However, this approach does not allow us to take into account the opinion of residents of municipalities as subjects of tax efforts, about the effectiveness of budget expenditures. Taking into account the importance of social and spatial components, it is proposed to focus on an approach that includes indicators of conflict (the opinion of residents about their vision of security of living in a particular territory) and statistical data on local budget expenditures.

The results of assessing the relationship between indicators that characterize the effectiveness of municipal budget spending in St. Petersburg: a factorial indicator - tax revenues to the local budget, and a performance indicator - the expenditures items to ensure the quality of life are below (Table 1). 
Table 1. Results of assessing the relationship between indicators that characterize the efficiency of municipal budget spending in St. Petersburg ${ }^{\mathrm{a}}$

\begin{tabular}{|c|c|c|c|}
\hline $\begin{array}{c}\text { Factorial } \\
\text { indicator }\end{array}$ & Result indicator & $\begin{array}{c}\text { Correlation } \\
\text { coefficient }\end{array}$ & $\begin{array}{c}\text { Type of } \\
\text { relationship }\end{array}$ \\
\hline Tax revenue & $\begin{array}{c}\text { Expenditures on housing and } \\
\text { communal services }\end{array}$ & 0.72 & Straight, strong \\
\hline Tax revenue & Expenditures on education & 0.52 & Straight, medium \\
\hline Tax revenue & $\begin{array}{c}\text { Expenditures on culture, } \\
\text { cinematography }\end{array}$ & 0.81 & Straight, strong \\
\hline Tax revenue & $\begin{array}{c}\text { Expenditures on physical culture } \\
\text { and sports }\end{array}$ & -0.09 & Practically absent \\
\hline Tax revenue & Expenditures on social policy & 0.78 & Straight, medium \\
\hline Tax revenue & $\begin{array}{c}\text { Expenditures on national security } \\
\text { and law enforcement }\end{array}$ & 0.02 & Practically absent \\
\hline
\end{tabular}

${ }^{\mathrm{a}}$ The author's calculation.

Based on the correlation analysis, the author has found that expenditures on cultural events, social policy, and housing and communal services are the priority expenditures of the local budgetss for all districts of St. Petersburg. At the same time, budget expenditures on physical culture, sports and life security are very low.

To assess the effectiveness of management development the author has calculated fiscal sustainability coefficient (hereinafter - FSC) describing the ratio of revenues to local budgets and expenditures on specific budget purpose - life security, housing and communal services, education, culture, physical culture and sport, social policy (Table 2).

Table 2. The coefficient of fiscal sustainability for the districts of St. Petersburg ${ }^{\mathrm{a}}$

\begin{tabular}{|c|c|}
\hline District & Fiscal sustainability coefficient (FSC) \\
\hline Admiralteyskiy & 1.65 \\
\hline Vasileostrovskiy & 1.24 \\
\hline Vyborgskiy & 1.33 \\
\hline Kalininskiy & 1.19 \\
\hline Kirovskiy & 1.19 \\
\hline Kolpinskiy & 0.33 \\
\hline Krasnogvardeyskiy & 1.19 \\
\hline Krasnosel'skiy & 1.04 \\
\hline Kronshtadtskiy & 0.57 \\
\hline Kurortny & 0.61 \\
\hline Moskovskiy & 1.41 \\
\hline Nevskiy & 1.14 \\
\hline Petrogradskiy & 1.22 \\
\hline Petrodvortsovy & 0.86 \\
\hline Primorskiy & 1.38 \\
\hline Pushkinskiy & 0.64 \\
\hline Frunzenskiy & 1.40 \\
\hline Tsentral'ny & 2.30 \\
\hline
\end{tabular}

${ }^{\mathrm{a}}$ The author's calculation.

In this case, the FSC is in the range from 0.33 to 2.30 , while the higher the coefficient value, the greater the amount of tax revenues to the local budget in a particular territory of the megalopolis, therefore, the local budget is more stable. If the FSC $>1$, then tax revenues to the local budget exceed local budget expenditures on social services, housing and communal services, and security. If the $\mathrm{FSC}<1$, then tax revenues are not sufficient for spending on social services, housing and communal services, and security. 
For transformation and normalization, the most significant social indicators of life security in the districts of St. Petersburg on the basis of sociological surveys of the population opinion are proposed to use as input indicators of conflict nodes:

- $X_{1}$ - share of residents who feel protected or rather protected from crime, $\%$,

- $X_{2}$ - share of residents, feel safe or rather safe on the road, $\%$.

When proceeding transformation the dimensionless value of input indicator $X_{i}^{\prime}$ changes from 0 (if $X_{i}=X_{\min }$ ) to 1 (if $X_{i}=X_{\max }$ ). The indexes for each territory have been calculated on a cumulative basis.

The security index (hereinafter - SI) is calculated for the districts of St. Petersburg as sum of the normalized dimensionless values of the input indicator $X_{i}^{\prime}$ according to formula (1) by the groups of conflict nodes indicators (Table 3 ).

Table 3. Cumulative assessment of conflict nodes by St. Petersburg districts ${ }^{\mathrm{a}}$

\begin{tabular}{|c|c|c|c|}
\hline District & $X_{1}$ & $X_{2}$ & SI \\
\hline Admiralteyskiy & 0.82 & 0.58 & 1.40 \\
\hline Vasileostrovskiy & 0.59 & 0.47 & 1.05 \\
\hline Vyborgskiy & 0.58 & 0.43 & 1.01 \\
\hline Kalininskiy & 0.00 & 0.33 & 0.33 \\
\hline Kirovskiy & 0.03 & 0.23 & 0.26 \\
\hline Kolpinskiy & 0.41 & 0.75 & 1.16 \\
\hline Krasnogvardeyskiy & 0.27 & 0.00 & 0.27 \\
\hline Krasnosel'skiy & 0.16 & 0.26 & 0.42 \\
\hline Kronshtadtskiy & 0.55 & 1.00 & 1.55 \\
\hline Kurortny & 0.85 & 0.54 & 1.39 \\
\hline Moskovskiy & 1.00 & 0.42 & 1.42 \\
\hline Nevskiy & 0.20 & 0.10 & 0.30 \\
\hline Petrogradskiy & 0.51 & 0.40 & 0.90 \\
\hline Petrodvortsovy & 0.33 & 0.41 & 0.74 \\
\hline Primorskiy & 0.67 & 0.53 & 1.20 \\
\hline Pushkinskiy & 0.81 & 0.36 & 1.17 \\
\hline Frunzenskiy & 0.18 & 0.46 & 0.64 \\
\hline Tsentral'ny & 0.43 & 0.03 & 0.47 \\
\hline
\end{tabular}

${ }^{\mathrm{a}}$ The author's calculation.

In this case, the security index ranges from 0.30 to 1.55 , and the higher the value of the security index, the higher the level of security in a particular area of the megalopolis.

The results of the conjugate analysis of the efficiency of local budget expenditures and conflict nodes by the districts of St. Petersburg are shown below (Table 4). 
Table 4. Differentiation of megalopolis's districts by the efficiency of local budget expenditures and potential assessment of economic security (on the example of St. Petersburg) ${ }^{\mathrm{a}}$.

\begin{tabular}{|c|c|c|c|}
\hline \multirow{2}{*}{ FSC } & \multicolumn{3}{|c|}{ SI } \\
\hline & More 1.51 & $1.0 \div 1.50$ & $0.00 \div 0.99$ \\
\hline More 1.51 & - & Admiralteyskiy & Tsentral'ny \\
\hline $1.00 \div 1.50$ & - & $\begin{array}{c}\text { Vasileostrovskiy } \\
\text { Vyborgskiy } \\
\text { Primorskiy } \\
\text { Moskovskiy }\end{array}$ & $\begin{array}{c}\text { Kalininskiy } \\
\text { Kirovskiy } \\
\text { Krasnogvardeyskiy } \\
\text { Nevskiy } \\
\text { Krasnosel'skiy } \\
\text { Frunzenskiy } \\
\text { Petrogradskiy }\end{array}$ \\
\hline $0 \div 0.99$ & Kronshtadtskiy & $\begin{array}{c}\text { Pushkinskiy } \\
\text { Kolpinskiy } \\
\text { Kurortny }\end{array}$ & Petrodvortsovy \\
\hline
\end{tabular}

${ }^{\mathrm{a}}$ The author's calculation.

The study of efficiency of local budget expenditures of megalopolises within the proposed approach involves the study of various groups of security indexes. Residents' vision of life security in the territory presents the social aspects and comprises the social and the subjective component of conflict potential. The group of statistic data on local budget expenditure comprises the objective component and shows how much and in what directions a territory is inefficient that means expenses for various budget purposes are not covered with tax revenues. The conjugate analysis of two groups of indicators makes possible to assess the level of the efficiency of local budget expenditures on ensuring favorable living conditions in various areas of the city and partly explains why a particular area wins in the opinion of residents, despite the low level of security according to statistics.

In general, the results of the study allow us to make a conclusion about the level of economic security in the territory of the metropolis.

\section{Summary}

According to the analysis of the efficiency of local budget expenditures by St. Petersburg districts three groups of territories have been defined: 1) the districts which local budgets have the greatest fiscal stability - Tsentral'ny and Admiralteyskiy districts (FSC > 1.5);2) the main group of districts in which tax revenues are sufficient to cover expenditures on social services, housing and communal services, and security: Vasileostrovskiy, Vyborgskiy, Primorskiy, Moskovskiy, Kalininskiy, Kirovskiy, Krasnogvardeyskiy, Krasnosel'skiy, Nevskiy, Petrogradskiy, Frunzenskiy districts $(\mathrm{FSC}=1 \div 1.5)$; 3) the districts with low budget sustainability - Kolpinskiy, Kronshtadtskiy, Kurortny, Petrodvortsovy, Pushkinskiy (FSC $<1$ ).

According to the analysis of economic security social aspect, reflected in the residents ratings of security, two groups of territories have been defined: 1) districts in which residents feel most protected are Vyborgskiy, Vasileostrovskiy, Kolpinskiy, Pushkinskiy, Primorskiy, Kurortny, Admiralteyskiy, Moskovskiy, Kronshtadtskiy (SI = 1.01 $\div 1.55$ ); 2) districts in which residents feel less protected are Kirovskiy, Krasnogvardeyskiy, Nevskiy, Kalininskiy, Krasnosel'skiy, Tsentral'ny, Frunzenskiy, Petrodvortsovy (SI $=0,26 \div 0,90$ ).

According to the conjugate analysis of conflict nodes and FSC assessments are conformed in the districts: Admiralteyskiy (high level of efficiency of local budget expenditure, the residents feel sufficiently protected), Vasileostrovskiy, Vyborgskiy, Primorskiy, Moskovskiy (balanced efficiency of local budget expenditure, the residents feel protected), Petrodvortsovy (low efficiency of local budget expenditure, the residents feel unprotected). 
In Tsentral'ny and Kronshtadtskiy districts, there is a discrepancy in the level of economic security and the level of covering local budget expenditures with tax revenues on security. In Tsentral'ny district, there is a low level of economic security, but high efficiency of local budget expenditures; in Kronshtadtskiy district, there is a high level of security, but insufficient tax revenues to cover the costs of security, social services, and housing and communal services.

In Kalininskiy, Kirovskiy, Krasnogvardeyskiy, Nevskiy, Krasnosel'skiy, Frunzenskiy, and Petrogradskiy districts, residents feel the least protected, but tax revenues are sufficient to cover the expenditures on security, social services, and housing and communal services.

In Pushkinskiy, Kolpinskiy, and Kurortny districts, tax revenues to local budgets are not enough to cover the need for security, but residents believe that the necessary level of quality of life has been achieved in the districts.

The article has been prepared as part of the work on the grant of St. Petersburg state University of architecture and construction №181/27.06.2019 for implementation of scientific research in the 2019/20 academic year under the Program of encouraging young scientists.

\section{References}

1. N. V. Vasiljeva, Bulletin of Baikal State University, 1, 117-125 (2015), doi: 10.17150/1993-3541.2015.25(1).117-125

2. V. B. Shuba, Finance, money, investments, 8-9 (8), 9-15 (2003)

3. V.V. Mishchenko, Economics and innovation management, 2, 51-60 (2018), doi: 10.26730/2587-5574-2018-2-51-60

4. E. B. Shuvalova, M. A. Solyarik, J. S. Zakharova, Statistics and Economics, 3, 51-54 (2016), doi: https://doi.org/10.21686/2500-3925-2016-3-51-54

5. I. V. Balynin, RUDN Journal of Public Administration, 4, 391-396 (2018), doi: 10.22363/2312-8313-2018-5-4-391-396

6. I. V. Balynin, Finance and credit, 30, 48-59 (2015)

7. M. Pacione, Urban Geography: a Global Perspective, 720 (2001)

8. Z. L. Miller, The social sciences go to Washington: The politics of knowledge in the postmodern age, 181-213 (2004)

9. E. Swyngedouw, Science as culture, 2, 95-104 (2006)

10. J. Stadelbauer, Global city: theory and reality, Mega-cities as a conflict of space ed N. A. Sluka (Avanglion, Moscow, 2007), 66-78

11. T. N. Orlovskaya, IOP Conf. Series: Materials Science and Engineering (to be published)

12. T. Orlovskaya, S. Ershova, E3S Web of Conferences, 135, 03054 (2019), doi: https://doi.org/10.1051/e3sconf/201913503054

13. T. N. Orlovskaya, Risk management in the economy: problems and solutions, 264-271 (2018), doi: http://doi.org/10.18720/SPBPU/2/id19-36

14. S. V. Yavon, Azimuth of Scientific Research: Economics and Administration, 2(23), 376-380 (2018)

15. E. G. Animitsa, N. Yu. Vlasova, Ya. P. Silin, Urban policy: theory, methodology, practice ed A. I. Tatarkin (IE RAS, Yekaterinburg, 2004)

16. E. A. Volosnikova, Tomsk State University Journal of Philosophy, Sociology and Political Science, 1 (17), 107-113 (2012) 